\title{
Sonic Necessity and Compositional Invention in \#BluesHop:
}

\section{Composing the Blues for Sample-Based Hip Hop}

\section{Introduction}

\author{
It's no doubt that there's a connection [between the blues and hip-hop]. Hip-hop is \\ definitely a child of the blues. And I think you gotta know the roots to really grow. It's \\ [like] knowing your parents, it's like knowing your culture, so you could be proud of that \\ culture and take it to the world. ${ }^{1}$
}

From Memphis Minnie's 1930 talking-blues hit Frankie Jean², through to rapper Nas's collaboration with his father-jazz-blues musician Olu Dara-on Bridging the Gap ${ }^{3}$, Abdominal and The Obliques' Sitting Music ${ }^{4}$ and, most recently, Amerigo Gazaway's B.B. \& The Underground King $\mathrm{z}^{5}$, recorded music history provides ample evidence of a close relationship between the Blues and Hip Hop. Rappers proclaim their affiliation with the Blues in their statements, lyrics and music, and historians and musicologists draw parallels between the sociopolitical backgrounds and narrative approaches of the two genres ${ }^{6}$. In Can't Stop Won't Stop, Jeff Chang observes that "if blues culture had developed under the conditions of oppressive, forced labor, hip-hop culture would arise from the conditions of no work."7 Describing his retrospective discovery of the Blues via Muddy Waters's Electric Mud ${ }^{8}$ album, rapper Chuck D of Public Enemy explains:

I was sparked about the blues as a beat digger coming across an album of immense layers and well-played sounds. [...] Myself and my co-producer Gary G-Whiz fell in love with the record, a psychedelic trip replaying and singing Muddy's classics of the past. ${ }^{9}$ 
In this statement, Chuck D not only identifies with blues music, but elaborates on the construction, arrangement and production of a later blues recording, which resonates with Public Enemy's heavily layered production style and allows him a rap musician's sonic window onto the past. Chuck D goes on to say that "being a so-called veteran of the genre labeled hiphop and rap music, you can't help being a musicologist, or at least a student of music, by default." ${ }^{\prime 10}$

Yet despite many of the thematic and cultural similarities celebrated between rap music and the Blues, the reality of their musical relationship and crossover reveals a number of tensions. One could argue that hip hop music is by default inter-stylistic, and since its very inception it has depended on phonographic segments from other musical styles in order to function and exist. DJ Kool Herc carried over the sound-system tradition of performing extended instrumentals using turntables from Jamaica to New York, where he replaced the Reggae dubs with Funk breaks ${ }^{11}$ and provided a rhythmical foundation for $M C s^{12}$ to rap over. ${ }^{13}$ The practice elevated the funk drum-break to 'building block of choice' for future hip hop productions, and Funk-in its various guises-remained a referential mainstay throughout all eras of hip hop composition. James Brown's Funky Drummer ${ }^{14}$ became the most sampled song in popular music history ${ }^{15}$, powering the majority of East Coast's boom bap productions ${ }^{16}$, while P-funk inspired West Coast's synthesizer-driven divergence via interpolations and live performance ${ }^{17}$. As a result, the lion's share of rap releases became literally powered by late 1960s and 1970s Funk and Soul, either by way of phonographic sampling or through compositional referencing, and although Blues samples do feature in Hip Hop, it will be important to question their lesser presence when compared to Funk and Soul sampling, despite Rap's otherwise celebrated affiliation to the Blues. In other words, why did the Blues not become the first sampling choice or main compositional reference in hip hop production? If there are extensive thematic, cultural 
and even philosophical affiliations between the two genres, are there sonic and musical factors deterring a more integrated cross-genre actualization? What can we learn from the successful case studies of congruent merging between the two genres, and how can this educate further inter-stylistic experiments? Finally, can these function as a lifeline for a practice that may be running low on renewable raw materials (i.e. phonographic samples)? In the words of hip hop producer Domino cited in Schloss:

I just think that, now, you're getting to the point where ... you're running out of things to find. And so a lot of the best loops have been used already. I mean, there's some stuff out there, I'm sure. There always will be stuff. But now it's like, in order to stop recycling things, you gotta just take pieces and make 'em into a whole new thing. ${ }^{18}$

\section{Methodology}

To answer these questions and consequently inform relevant creative practice there are a number of areas that require closer examination. Firstly, if sampling is the predominant methodology in hip hop creation, then the musical and sonic qualities of blues recordings need to be analyzed from the perspective of their sample 'appropriateness'. This requires aural analysis of representative blues works that feature within rap songs as sampled sources. In her article 'Records that Play: The Present Past in Sampling Practice', Vanesa Chang explains:

The successful pursuit of new samples has, as its limit, the producer's capacity to hear musical possibility in a song, to listen for connections that may not currently exist in the song, to perceive aural spaces where they might not be obvious. This requires conceiving of sound as plastic material, and not as a finished product. ${ }^{19}$

Furthermore, and in response to the growing practices of interpolation ${ }^{20}$, original composition, and live performance within hip hop production, it will be important to consider issues of stylistic authenticity and sonic impact arising from these alternative methodologies. A large part 
of the existing literature focuses on the relationship between phonographic samples and hip hop 'realness', or authenticity. ${ }^{21}$ Using intertextual analysis, the article will aim to identify the musical and 'sonic signatures' 22 that render audio material preferential to samplists. It will then explore production approaches that may prove effective in infusing original material with these qualities, whilst supporting musical innovation and originality. Marshall discusses this dynamic in the work of live hip hop band The Roots:

...the degree to which the Roots' music indexes hip-hop's sample-based aesthetic serves as a crucial determinant of the group's "realness" to many listeners. At the same time, the Roots' instrumental facility affords them a certain flexibility and freedom and allows them to advance a unique, if markedly experimental, voice within the creative constraints of "traditional" hip-hop's somewhat conservative conventions. ${ }^{23}$

On the other hand, in the cases where sampling methodologies do have the potential to interact with original composition and performance in a synchronous or near-synchronous context, it may be fruitful to consider them as active determinants in the shaping of this material, as opposed to mere agents that enable the manipulation of a 'passive' recorded past. Consequently, and following an examination of the literature on sampling practices and production as 'composition'24, the methodology will involve an applied stage of creative practice, where original blues composition, improvisation and performance interact with an integrated sample-based production process.

The effect of studio practices on the evolution of musical aesthetics has precedents that date back to the very beginning of phonography and, in the case of the Blues, Robert Johnson analyst Eric W. Rothenbuhler has supported that Johnson's "music reflected a then nascent recording culture (...which) was influenced by recorded music and showed signs of being composed and performed with attention to a kind of for-the-record aesthetic." 25 But when a 
studio process enables the creation of blues content that is designed to feed sample-based composition, this may be described as a case of pursuing a kind of 'meta'-record aesthetics, where the meta-genre (Hip Hop) not only digests, but shapes the source-genre. The degree, dynamic and potential outputs of this interaction become the subject of reflexive analysis, extrapolating further on the effect of sampling technologies on inter-stylistic synthesis, morphing and the creation of cross-genres. As Albin Zak states in The Poetics of Rock, "(i)n the development of a music so stylistically dependent upon machinery, the history of technology and the history of musical style are linked."26

\section{Samplin' and Tumblin'}

Commencing with the analysis of representative works, three different cases have been selected here: Nas's Bridging the Gap ${ }^{27}$ referencing Muddy Waters's Mannish Boy ${ }^{28}$; Amerigo Gazaway's mashup The Trill is Gone ${ }^{29}$, sampling B.B. King's The Thrill Is Gone ${ }^{30}$; and Abdominal and the Obliques' track Broken, from their album Sitting Music ${ }^{31}$.

[Case 1:] Bridging the Gap is a collaboration between rapper Nas and his father Olu Dara, a jazz-blues musician who performs lead guitar, trumpet and harmonica on the track. Producer Salaam Remi performs bass, guitar and drums, and session musician Vincent Henry is credited with the remainder of the live performances, namely baritone sax, harmonica and strings. Although Mannish Boy receives no sampling or interpolation credit-and only father, son and producer are credited with writing and composition - the central guitar and harmonica motif can rather clearly be identified as a faster (and melodically sparser) homage to Muddy Waters's and Junior Wells's interaction on Mannish Boy, which is further accentuated by the melodic similarities in Olu Dara's chorus. Olu Dara's lyrics, however, are different to Muddy's version and this, perhaps, legitimizes Dara's reclaiming of the motif: 
See I come from Mississippi

I was young and runnin' wild

Ended up in New York City, where I had my first child

I named the boy Nasir, all the boys call him Nas

I told him as a youngster, he'll be the greatest man alive ${ }^{32}$

This is consistent with an early blues tradition of shared motifs and a more inclusive notion of composition, which Rothenbuhler describes as follows:

In the early blues tradition, as in most oral cultures, there was little emphasis on composition as we define it and value it today. Both lyrics and music were combinations of standard figures and phrases, a given performer's own adaptations or inventions, and new phrases invented or chosen from the stock to fit the situation of performance. ${ }^{33}$ Ironically, this compositional position has a lot in common with Hip Hop's sampling philosophy and production ethics. Yet the adapted introductory motif here retains its blues-derived triplet feel (12/8), which cannot quite bridge the gap with Hip Hop's funk-derived reliance on common time (4/4). Salaam Remi does not attempt to resolve the tension, instead structuring the production around a clearly defined 'duality' of $12 / 8$ choruses (featuring sung parts by Olu Dara) and 4/4 verses (featuring Nas's raps). The 12/8 blues hook that introduces the song is suddenly sped up and re-appropriated in common time at 0:33, punctuated by Nas's "let's go" shout initiating the verse figure, and resembling a sample-based gesture which-although highly swung in its relationship to the syncopated drum part-nevertheless remains in $4 / 4$. The verses are constructed around a two-bar repetition of the live drums and the guitar and harmonica riff, with occasional solo harmonica flourishes, sixteenth snare drum fills, and strings that build-up at the end of four or eight-bar sequences. Despite the construction of the verses out of live performances, the main verse 'loop' here conveys a sample-based approach, whether the drum pattern and riff repetition are in fact constructed with the use of a sampler or looped around 
within a DAW ${ }^{34}$. The up-front placement of the drum mix, its consistent two-bar repetition, the rhythmical cuts and stops of the beat, and the tight placement of what feels like a 'chopped'35 version of the blues motif against it, convey a clear sample-based sensibility. Furthermore, the recording and mix sonics imprinted upon the blues performances are reminiscent of vintage production qualities (such as lower fidelity and higher tube saturation, similar to mid-to-late 1950s Chess label recordings), which distances them from the more modern sonic signatures imprinted upon the drums and raps. The fact that multiple studios have been deployed for the completion of this track ${ }^{36}$, may suggest that the producer purposefully pursued particular erainvoking timbres from alternate technical setups when dealing with the different instrumental groups. The drum figure is reminiscent-both in its accents and sonics-of 1970s funk breakbeats, such as Clyde Stubblefield's drum break from Funky Drummer by James Brown ${ }^{37}$. The sonic differentiation is further exemplified by the different timbral qualities and spatial treatments on both Nas's and Olu Dara's voices, the former appearing more contemporary and congruent with a post-2000 rap aesthetic, the latter sign-posting towards a more distant-if somewhat generic-past. As such, Bridging the Gap highlights musical and timbral tensions between the Blues and Hip Hop, presenting the producer with rhythmical and sonic ultimata. Although the Blues are hereby 're-constructed' rather than phonographically sampled, Salaam Remi chooses to amplify the stylistic differences by dialing in structural and timbral polarities, resolving to a historically intermediate style-Funk-for his drum break, acting as a catalyst in bridging the gap.

[Case 2:] Amerigo Gazaway is a Nashville-based producer who is well known as a "chemist" 38 of the mashup creating "collaborations that never were" ${ }^{39}$. Having previously mixed Marvin Gaye's soul vocals with Mos Def's raps, and The Pharcyde's - West Coast - rhymes against Tribe Called Quest's - East Coast - instrumentals ${ }^{40}$, his work is identifiably sample- 
based. But he elevates the 'mashup' beyond its historical definition as a mere juxtaposition of two or more synchronized records. Through extensive sampling of smaller segments from multiple sources, sample manipulation, live recording, and computer programming, he is able to synthesize the numerous elements into a coherent whole of notable musicality. This is enriched by his considerable skills in live musicianship, which allow him to integrate organ, electric bass, electric piano, synthesizers, and turntables into the mix, effectively 'jamming' with the sampled musicians who "never were" in his studio. His method places him in the virtual seat of a producer who works with artistic 'ghosts' from the past, creating a metaphor of a more physical production paradigm. For B.B. \& The Underground Kingz, Soul Mates Records ${ }^{41}$ state:

Aptly titled "BB \& The Underground Kingz: The Trill is Gone," the producer seamlessly bridges the gap between hip-hop and its predecessor, the blues.

Crafting the album's bedrock from deconstructed samples of King's electric blues hits, Gazaway re-imagined what might have happened had King and UGK actually recorded in the same time and space. [...] Strategically looping and lacing Lucille's guitar licks and B.B.'s road tales with Bun B \& Pimp C's southern fried storytelling, Gazaway finds a sweet spot in the overlapping themes of his subjects' respective catalogs.

Amerigo adds: "I'm trying to get away from using that word (mashup), and trying to call it something like a conceptual collaboration."42 Gazaway's methodology may appear as a polar opposite to Salaam Remi's interpolation approach on the surface, because of the precedence of sampling over 'original' composition; yet he is able to achieve a more integrated co-existence between the two genres, moving away from distinct structural dualities or triplet-based time signatures forced into common time. This is partly due to his micro-sampling ${ }^{43}$ processes, but also because of characteristics inherent in the type and era of blues that he chooses to sample. On a track such as The Trill is Gone, he chooses B.B. King's 1969 version of The Thrill is Gone, a 
4/4 rendition of the 6/8 minor jazz-blues original, released by Roy Hawkins ${ }^{44}$ in 1951. The B.B. King version is characteristic of a late 1960s or early 1970s blues treatment as, by this point, the influence of Soul and Funk can be felt clearly on the Blues. The time signatures begin to favor common time, and many of the arrangements expand considerably to include larger sections (often brass and strings), contributing to more polished productions with larger ambient footprints and less mix saturation (particularly when compared to the mid-1950s Chicago blues referenced for Bridging the Gap). Similar characteristics can be heard on records by the other two 'King' contemporaries, Freddie King and Albert King (the latter exemplifying the soul-blues formula of Stax Records), with comparable sonic signatures on records such as Help Me Through the Day ${ }^{45}$ and $I^{\prime} l l$ Play the Blues for You, Pt. $1^{46}$ respectively. The tendency for R\&B-inspired, minor 4/4 blues in this era, with spacious arrangements and extended electric guitar solos (at tempos that range between 80 and $95 \mathrm{bpm})$, is particularly helpful in the hands of rap samplists such as Gazaway. The link with Funk has already been created on the source material, there are no time signature tensions to be resolved, and the extended instrumental sections provide multiple opportunities for sampling particular parts. Furthermore, the fuller arrangements enrich the sampled palette with wide frequency spectra, and the minor harmony is congruent with the dark mood of much modern Hip Hop. Characteristically, on The Trill is Gone, Gazaway diverts from the (funk-derived) hip hop habit of staying on the I chord for the duration of the song (which Bridging the Gap pays tribute to), and instead follows the harmonic movement of B.B. King's version. He reduces the tempo from approximately 90 to $78 \mathrm{bpm}$ (and consequently the tonality of the song from Bm to Am), but respects the i-iv-i-bVI-v(7) sequence of the 1969 version. He also re-arranges various instrumental guitar segments under the rapped verses, creating a classic 'call-and-response' blues signature between the guitar and vocals. Further 
additions include live organ lines for the later parts of the choruses, as well as backing vocals and ad-libs.

The resulting rich and pluralistic musical arrangement is characteristic of Southern Rap's divergence from East and West Coast Hip Hop in the mid-1990s ${ }^{47}$, justifying the inter-stylistic intentions here also from the perspective of Hip Hop's evolution. Amerigo consciously pays homage to both DJ Screw's slowed-down "chopped and screwed" sampling style and Pimp C's gospel-inspired use of live instrumentation ${ }^{48}$, regarding the latter as a pioneer in "making Southern Rap music that was melodic and had harmony" and "blending the old with the new" ${ }^{49}$ In other words, Gazaway finds commonalities between later (funk/soul-contaminated) Blues and more recent hip hop divergences, in order to allow for richer harmonic progressions that support this complimentary meeting of genres. Through these choices he demonstrates a positive case of "trans-morphing" 50 , where he not only successfully mixes the two genres but arguably creates a new, hybrid one; one that sits comfortably within the evolutionary narrative of Southern Rap. The choice to pitch and slow down the instrumental by two semitones and approximately $12 \mathrm{bpm}^{51}$ supports idiosyncrasies characteristic of Southern Rap subgenres, and this may be one of the most crucial decisions Gazaway makes initially. As a consequence, he accepts the reduced frequency 'presence' of the original recording's spectrum, which in turn allows him to place many of the blues samples 'behind' the programmed beat as far as the 'depth' perspective of the mix is concerned. He also abuses the two sides of the blues multitrack by widening it to an audible extent in order to allow for a distinct 'center-stage' placement for his newly programmed electronic kick and snare drums (characteristic of the subgenre's reliance on Roland TR-808 drum machine timbres). The original electric piano parts are exposed on the right side of the stereo image and he chops and edits them at the end of the eight-bar sections to enhance their rhythmical effect. His synthetic high-hats sit comfortably on top of 
otherwise mildly equalized instrumental elements (another result of the pitching down and, perhaps, his further equalization of the samples), interplaying between eighths, sixteenths and thirty-seconds in the high-hat programming. Finally, the expansive ambience of the original blues mix enhances the combined, illusory 'depth' effect, giving the blues signature a distinctly haunting 'space' within the architectural landscape of the mashup; it feels like past and present are occupying separate sonic spaces.

In another production decision of key importance, Amerigo uses the Melodyne software to transform the original live electric bass into a MIDI part, which he then uses to trigger a "dirty south sub synth bass" at "the exact same shuffle, the exact same groove as the actual bass player that played on the record", serving the southern synth-bass sensibility but keeping "that human groove" ${ }^{52}$ Thus, the totality of the sonic characteristics described above appear intrinsically linked to musical decisions conceived as part of cross-genre mixing, informing the creative processes that follow in the applied leg of the article's methodology. In a move that mirrors his elegant sonic trans-morphing, Gazaway sums up the cross-genre journey in the title of his mashup, changing thrill to trill, a term simultaneously referring to Texas slang and a Southern Rap subgenre ${ }^{53}$. Finally, he identifies his contemporaries' fear of dealing with triplet subdivisions as the main reason behind the less frequent integration of Blues and Rap, a creative challenge that he wholeheartedly accepts on other tracks of the B.B. \& The Underground Kingz (2015) album by "working with it a little bit more, massaging it (further) and pushing it ... more" ${ }^{\prime 54}$.

[Case 3:] At the other extreme of the Blues-Rap spectrum are situated attempts at a fully live performed Hip Hop, borrowing from traditional blues composition and performance practices. Perhaps the most representative live hip hop band are The Roots, while Blakroc-the collaborative album between hip hop producer Damon Dash and rock group the Black Keys- 
also provides a relevant case. The Roots, however, owe more to Jazz, Funk and Soul than to Blues directly, and although the Black Keys are often referred to as a blues-rock act, Blakroc mixes alternative and garage rock influences in equal measure. Abdominal and The Obliques on the other hand, are one of the very few acts that receive the quintessential \#BluesHop tag in the online world, exemplifying the cross-genre as a hybrid of live instrumental performance and rapping. The group formed as a side project of Toronto rapper Andy Bernstein-known by his stage name as Abdominal, sometimes Abs-and released their album Sitting Music in 2012, providing a useful case-study of hybridization with its own compositional and sonic problematics. Thomas Quinlan provides the following review of the record on exclaim.ca: A mix of folk, blues and country (that) replaces the sampling and boom bap beats. Revitalized by a backing band — guitarist Andrew Frost and percussionist Colin Kingsmore- Abs is still rapping but with a smoother flow that sometimes becomes singing, while his band provide backing harmonies and hooks. [...] Sitting Music might not be your typical hip-hop album —Abs describes it as blues-hop and "middle-aged hiphop" - but it's great to see an artist striving to stretch his boundaries. ${ }^{55}$

The very inception of the project is a consequence of Andy Bernstein's reaction to growing older and wanting to experiment with more introspective lyrical themes, which according to him required a different sound and "some time apart" from what he describes as "traditional Hip Hop" ${ }^{56}$ In an interview with the author, Bernstein explains:

My whole career has been more (about) doing the straight-ahead rap stuff, like typical rap-beat-samples, that kind of thing. The idea behind (forming) the band was just really because I was getting older and I was finding (that) I wanted to tackle some new themes [...] slightly more introspective themes, look at some vulnerable kind of topics. So, it just didn't feel right to me to have the same -the usual - typical sample-based boom bap rap beats for those types of songs. That was really the main reason for me to put the 
band together, just to kind of get like a mellower, quieter sound that would better fit the themes of these new types of songs. ${ }^{57}$

Abdominal, furthermore, disagrees with the notion of a direct link existing between rap authenticity and the sample-based method, because Hip Hop "does not equal one particular sound, it's more (of) an approach, an aesthetic [...] using what's around you and crafting it to form something new, whether it's using samples, whether it's, oh you know, I know this guitarist..."58 On single Broken, Bernstein, Frost and Kingsmore use percussion, and acoustic, electric and slide guitars, all recorded in a domestic basement with household objects used as separation baffles, and vocals overdubbed at the rapper's home studio. Abdominal's vision for the album was to capture the sonic of "just three dudes sitting on a porch playing", something they achieve by focusing on simultaneous performances as much as possible, allowing recording 'spill'59 to take place, and not overly polishing the post-production process. ${ }^{60}$

The general harmonic progression of I-bIII-I-IV-V in the choruses and I-bIII-ii-V in the verses, with frequent usage of passing chords and extensions, and the laid-back performing style over a slow tempo, conjure a 'swamp blues' feel; but there is a definitive hip hop influence on the hybridization of the composition and arrangement. The percussive beat is simplified to quarter and eighth accents resembling a drum-machine pattern, with shakers added progressively to emulate programmed high-hat sixteenths. At 01:43 Frost and Kingsmore perform a quarter-note 'stutter' echoing a sample-based repeat which lasts one additional bar, while on many occasions (i.e. at 1:30, 2:50 and 3:23) there are complete instrumental stops resembling DJ 'cuts' ${ }^{61}$. The main acoustic guitar sequence repeats throughout the verses assuming a 'looped' function, often ending the four-bar sections with rather exposed and mechanized quarter strums, 'marking time' so to speak. Although the intention here may not be about pursuing a sampled or programmed production texture, it is clear that the musicians' 
experience of Hip Hop, and their catering for the rapped verses, drive their compositional, arranging and structural decisions towards an effective hybridization. One that is thematically supported by the lyrics and the group's open-minded approach to experimentation in negotiating the two genres. Notably, they remain less experimental during the rapped verses, with a simpler harmonic progression and a strict four-bar repetition, while for the sung choruses they support the melody by leaving the tonic for the flat third chord, then returning to the tonic before the closing IV-V-I turnaround. The resulting five-bar chorus cycle feels supportive of the sung melody, giving the hook a distinctive if peculiar feel, while parallels can be drawn to early recorded country or folk blues where performers would extend their own accompaniments to cater for the uniqueness of their melodic or lyrical lines. ${ }^{62}$ It is not a surprise that out of the three case studies, it is the live blues-hop production that presents the most compositional freedom, but what is important here is the influence of the meta-genre on the traditional form, even without its form-shaping technologies directly on hand (i.e. the use of samplers and DAWs). In effect, the sampling practices that have shaped the 'meta-genre' are not hereby utilized directly, but their stylistic aftermath is exercised by the musicians in absentia, shaping the very rhythm, arrangement and structure of their blues-inspired performances.

\section{Meta-jamming: setting up the inter-stylistic experiment}

As part of the wider research project examining the application of vintage production techniques on contemporary Hip Hop, more than eight hours of original blues content have been composed in preparation for the sampling phase, referencing blues styles from the 1950 s to the 1970 s. For the purposes of this examination, late-1960s to early-1970s minor blues examples have been referenced, such as the southern Blues that came out of Shelter Records in Texas, and Stax Records in Memphis. The aim has been to create a relevant applied context, 
which will welcome practical exploration of the findings from the three case studies above: musical and sonic characteristics that reflect the first two case studies, but also compositional freedom reflected in the third. For this particular experiment, a fifteen-minute improvisation has been conceptualized and then recorded by overdubbing acoustic drums, electric bass, upright piano, electric Rhodes piano, electric guitar, and shaker. Loosely inspired by the aforementioned references, the improvisation has taken place over an eight-bar iv-i-V(7)-i harmonic progression (for the verses) and a bVI(7)-i-V(7)-i variation (for the bridges or choruses), at a harmonic speed of two bars per chord, a tempo of $85 \mathrm{bpm}$ and a time signature of $4 / 4$.

TABLE 1: HARMONIC PROGRESSION OF THE BLUES RECORDING

\begin{tabular}{|r|c|c|c|c|c|c|c|c|}
\hline Bars & 1 & 2 & 3 & 4 & \multicolumn{2}{c}{5} & 6 & 7 \\
8 \\
\hline Verse & iv & iv & i & i & V(7) & V(7) & i & i \\
\hline $\begin{array}{r}\text { Bridge } \\
\text { Chorus }\end{array}$ & bVI(7) & bVI(7) & i & i & V(7) & V(7) & i & i \\
\hline
\end{tabular}

The drums were recorded to a metronome click and the rest of the instrumentation in synchronization to the drums, with the aim of aiding the editing processes of the forthcoming sampling phase. ${ }^{63}$ The duration of the recording extended to fifteen minutes - or 642 barssupporting the development of instrumental synergies and furnishing the sampling phase with a rich palette of options. The cyclic blues form consisted of pattern and dynamic variations centered around a main electric bass guitar motif often coupled with the electric guitar (a figure frequently employed at Stax by Albert King and bassist Duck Dunn of Booker T. and the M.G.'s), while the electric Rhodes piano supported the harmony and rhythm with chordal work in the middle register. The upright piano provided rhythmical and harmonic support initially, then delved into solo improvisation as the track progressed. The drums gradually developed from 
simple eighth bass-drum and snare-drum patterns using the cross-stick on the snare, to more syncopated and swung sixteenth accents progressively employing the full snare. These were consciously performed to mirror a range of references ${ }^{64}$, again with the aim of enriching the potential sampling pool of the later phases. After minor macro-editing of the performanceswhich aimed at preserving the micro-level interaction between instrumental performances and their resulting 'groove', but nevertheless removing any content of no use- -125 segments of half, single, and dual bars were deemed as worthy samples, each segment representing no more than a single chord in the harmonic progression. These were then exported as synchronized multi-track components and (given the track-count of fifteen channels for most parts of the structure) resulted in 1,854 audio files ${ }^{65}$. The synchronized stereo segments were brought into another DAW for mixing, utilizing software emulations of representative hardware technologies for the era. Particular attention was directed towards microphone pre-amps, mixing desk summing and recording format (tape, vinyl) coloration, characteristic of vintage sonic signatures imprinted on material that would frequently be favored for sampling. Master tape and vinyl record emulations of the stereo files were prepared for each segment of the multi-track, and the mixed results were exported as 24-bit wave files, compatible with Akai's MPC Renaissance music production controller, which was to be used extensively in the following sampling phase ${ }^{66}$. Finally, each segment or 'chop' was assigned to a drum pad on the MPC, taking up most of its eight banks of sixteen pad locations (a maximum of 128 per program ${ }^{67}$ ) to fuel the following phase.

\section{[Please insert Video 1 here]}




\section{Chopping the Blues: sample-based composition}

A lot has been written about 'sample-based' composition, some of it polemic ${ }^{68}$ and some supportive ${ }^{69}$, while much of the literature is focused on the ethical and legal dimensions of what is regarded as new or original work ${ }^{70}$. Although, as we have seen above, the Blues themselves challenge Eurocentric notions of composition, in this particular case, the publishing and mechanical constraints that would limit sample-based composition are removed by virtue of the author being both sampled and samplist. This context allows for a focused reflexive analysis of the interaction between sampling practice and the construction of pre-recorded material, without diluting the question with peripheral concerns. Furthermore, it will be useful to extrapolate on potential synergies resulting from this closer relationship between the two functions: composer as content creator, as well as content 'manipulator'.

The Akai MPC range facilitates a particular sampling workflow due to its interface design, operating system, but also a number of inherent sonic characteristics. The drum pads situated on top of its interface - for all of its hardware, software or hybrid incarnations -invite a percussive style of triggering of musical material, while the Roger Linn-derived rhythmic quantization (with its characteristic swing and inherent timing imperfections) is the subject of much reverence from scholars and practitioners alike ${ }^{71}$. Similarly, the 'sound of the MPC' gets particular attention in press and literature, a characteristic that is attributed to the lower sampling resolution of older models, resulting in lower fidelity and a dynamically limited headroom that is actually helpful to beat 'placement' within the mix ${ }^{72}$. The MPC Renaissance has been chosen here as a later incarnation of this archetypical hip hop production tool (albeit one with improved computer integration, helpful to the scope of this experiment), effectively seen as a hip hop 'instrument' that inspires particular musical utterances. 
Following experimentation with the sequence and timing of the chopped bars derived from the original composition, and making use of the MPC drum pads, it was possible to create new rhythmical and harmonic combinations by triggering shorter segments and creating reimagined sequences that were never performed on the original recording. Depending on the length of the segments used, the tempo of the original piece was still perceptible for any sample longer than an individual percussive hit, so the whole program was detuned by two semitones, consequently reducing the tempo of the segments by approximately $12 \mathrm{bpm}^{73}$. A typical boom bap practice is to set a program's polyphony to mono, so that each segment triggered, mutes the previous one already playing ${ }^{74}$. Although this was historically practiced partly as a means to obscure the origin of phonographic samples (by keeping them shorter, and presenting them in re-imagined orders), two positive side-effects of the process were a highly rhythmical effect, and preservation of clarity in the harmonic progression of newly constructed patterns (avoiding the juxtaposition of overlapping chords). Employing this practice for both aesthetic and pragmatic reasons, the following sequences were composed, stemming from the original 'chops':

TABLE 2: HARMONIC PROGRESSION OF HIP HOP PRODUCTION

\begin{tabular}{|c|c|c|c|c|c|c|c|c|}
\hline Bars & 1 & 2 & 3 & 4 & 5 & 6 & 7 & 8 \\
\hline Intro 1 & iv iv i i & iv iv i i & iv ivi i & iv iv i i & & & & \\
\hline Intro 2 & i i i iv & i i i V & i i i V & i i bVI(7) V & & & & \\
\hline Verse & iv $[\times 4]$ & $\mathbf{i}[x 4]$ & iv $[x 4]$ & $\mathbf{i}[x 4]$ & $\begin{array}{l}\text { iv(sus } 4)[\times 2] \\
\quad \text { iv }[\times 2]\end{array}$ & $\mathbf{i}[\times 4]$ & $\begin{array}{l}\text { iv(sus4) }[\times 2] \\
\quad \text { iv }[\times 2]\end{array}$ & $\mathrm{V}(7)[\times 4]$ \\
\hline Bridge & bVI(7) $[\times 4]$ & $\mathbf{i}[\times 4]$ & bVI(7) $[\times 4]$ & $\mathbf{i}[\times 4]$ & bVI(7) $[x 4]$ & $\mathbf{i}[\times 4]$ & bVI(7) $[x 4]$ & $\mathrm{V}(7)[\times 4]$ \\
\hline Chorus & $i \mathrm{i}$ iv iv & i i iv iiø & i i iv iv & i i iv iiø & i i iv iv & i i iv iiø & $i \mathrm{i}$ iv iv & i i iv iiø \\
\hline
\end{tabular}

* each chord represents one of four beats in a bar 
The large range of samples exported provided multiple alternatives for each single-chord bar, with factors such as the richness of the frequency spectrum and the individual micro-motifs of included instruments becoming crucial in the selection process and triggering. Importantly, as can be seen in Table 2 above, the programming and re-organization of the segments allowed the construction of different sequences to the original, at altered harmonic speeds for most sections (generally faster when compared to the original recording, with speeds of two chords per bar and at times one chord per beat). It is interesting to note from the harmonic analysis that the programming and re-organization of the sampled segments created a number of harmonic departures, extensions or substitutions. Specifically, on the fifth and seventh bars of each verse, the segment chosen in support of the iv chord is a different one to that used in bars one and three, featuring a clear variation in the contained piano melody, and one that stresses the seventh scale degree, infusing the iv chord with a potential sus4 coloration. A similar occurrence can be observed in the chorus, where every other bar can be perceived as a halfdiminished ii chord (in place of the iv chord of bars one, three, five and seven). This is due to a passing note audible on the sampled electric bass part, which moves to the second degree of the scale and it is the result of an additional one-beat segment brought in on beat four of every even bar (bars two, four, six and eight of the chorus sequences). Despite the fact that these extensions and substitutions are open to interpretation, they are however suggested as a consequence of melodic content occurring inadvertently within the high number of sampled alternatives. The rap producer then has a choice to either exploit what is implied and augment it, or suppress it, through additional layering ${ }^{75}$. What's more, the sonic manipulation of sampled content within a sampler or during mix-down can further affect these harmonic choices. It is typical practice to equalize samples using a sampler's onboard filters in order to remove unwanted or clashing parts from the frequency spectrum, or to boost frequencies picking 
complimentary tones that work in the new context. This can accentuate or mask particular instrumental parts literally influencing the level of their contribution to the harmonic content. With regards to the rhythmical implications of the process, the monophonic triggering and muting, on the other hand, can create tightly syncopated results due to the placement of the new 'cut' (initiated by the percussive attack of the edit or a drum-hit on the first beat) against rhythmical subdivisions already present in the previously playing segment. In this example, this was further exploited by decimal alterations to the overall tempo, and the use of MPC's higher settings of swing quantization, which made any sixteenth triggering 'late,' and by consequence closer to the next event triggered. As a result, the original material here assumes new rhythmical qualities due to its placement and truncation within the programming order sequenced on the MPC. It could be argued, that the resulting sensibility is quintessentially Hip Hop: the meta-syncopation interacts favorably with the sampled material's internal syncopation, which may be a further pragmatic reason explaining why Hip Hop favors Funk and frequently cites an Afrocentric sonic past. Schloss explains:

A hip-hop beat consists of a number of real-time collective performances (original recordings), which are digitally sampled and arranged into a cyclic structure (the beat) by a single author (the producer). In order to appreciate the music, a listener must hear both the original interactions and how they have been organised into new relationships with each other. [...] And the formal structure may reflect both linear development (in the original composition) and cyclic structure (in its hip-hop utilization). ${ }^{76}$

Due to legal or content-related limitations in accessing favorable sampling material, however, much Rap music that is produced with cyclic priorities in mind, whilst exploiting the rhythmical tendencies described, it also tends to be harmonically more timid. This is in no way a criticism of the musical outputs of the practice - to which Schloss attributes a defining aesthetic 
value-but, in drawing a condition between limitation and results, we are able to explore the creative possibilities should the limitation be removed. The original compositional phase in this experiment has allowed for extended sampling opportunities, optimized synchronization, and direct access to instrumental-only material. It is in this context that inter-stylistic evolution can be pursued further, as Rap's rhythmical sensibility (a result of particular workflow and methodological practices) can be potentially combined with increased harmonic freedom. I believe that some of the answers to the long debate on sampling versus live performance in relation to hip hop authenticity, may lie in the grey area between these two polarities. After all, samples contain live musicianship per se, so it is the differentiating variables between the sample-based method and the live approach that are of interest. And although limitation may be the mother of invention, at least for particular eras of Hip Hop's trajectory, it may be of value to challenge Hip Hop's limitations, and then observe the tensions expressed against its overarching aesthetic. Despite live hip hop bands' best efforts to stay within the genre, the debate continues ${ }^{77}$. The Roots drummer and producer ?uestlove, has dedicated a large part of his professional life to achieving authentic hip hop sonics on his drum kit, but what he maypurposely-be missing is the meta-ingredient: the effect of the sample-based process upon his Funk. An effect that birthed the Hip Hop of the Golden Age ${ }^{78}$ and defined the boom bap subgenre. Schloss argues that:

It is in the relationship between the samples that the process of composition begins to exert a decisive influence as producers experiment with different patterns and approaches to organization. [...] In making their studios into laboratories, producers are making themselves into research scientists... ${ }^{79}$

[Please insert Video 2 here] 


\section{Conclusion}

Previous attempts at hip hop musicological analysis have dealt extensively with rapping and the poetics of the voice ${ }^{80}$, while the literature on sampling discussed above has dealt with the mechanics and aesthetics of the sample-based process and its interaction with phonographic content. This article has focused on the relationship between the sonic priorities of Hip Hop and the composition of original content, utilizing the Blues as a case-study and exploring the potential of inter-stylistic trans-morphing between its form and Hip Hop. Although the Blues share some of the cyclic structures that are mirrored in Hip Hop, they have also been utilized less than other forms of music in its sampling practices, thus presenting some unique rhythmical and harmonic problematics in the applied aspect of this examination. As Kyle Adams highlights regarding the problems of hip hop analysis:

The techniques developed for the analysis of Western art music, even when they can provide accurate descriptions of some of hip-hop's surface phenomena, often leave the analyst without a deeper sense of how hip-hop operates and why it seems to communicate so effectively with such a broad audience. ${ }^{81}$

This examination has attempted to delve into the mechanics of the creative practice in order to serve the musicological pursuit of hip hop analysis from a practice-based perspective. The exploration attempts to address a gap in the field identified by Simon Zagorski-Thomas in his book, The Musicology of Record Production:

Probably the largest imbalance, which is due to the analytical focus and the desire to establish a map of the theoretical landscape, is the lack of explicit discussion of how this theory should inform the practicalities of production. ${ }^{82}$

Although this research in no way offers an exhaustive typology of the creative opportunities that exist between the sample-based landscape and original composition, the examination has 
focused on rhythmical and harmonic interactions between the Blues and Hip Hop with a twofold intention: to systematically explore inter-stylistic synergies from a practice-based perspective, whilst navigating alternative creative avenues for Hip Hop's future evolution. 


\section{Bibliography}

Adams, Kyle. "The Musical Analysis of Hip-Hop." In The Cambridge Companion to Hip-Hop, edited by Justin Williams, 118-134. Cambridge, UK: Cambridge University Press, 2015.

B.B. King: The Life of Riley. DVD. Directed by Jon Brewer. Boulevard Entertainment, 2012.

Beer, David, and Barry Sandywell. "Stylistic Morphing: Notes on the Digitisation of Contemporary Music Culture." Convergence: The International Journal of Research into New Media Technologies 11 no 4 (2005): 106-121.

Bernstein, Andy. Interview by author. Skype interview. London, UK, May 21, 2016.

Caldwell, Brandon. "UGK/B.B. King Mashup 'The Trill Is Gone' Is as Awesome as You Think It Is." Houston Press. Accessed August 24, 2019. http://www.houstonpress.com/music/ugk-bb-king-mashup-the-trill-isgone-is-as-awesome-as-you-think-it-is-7887211.

Chang, Jeff. Can't Stop Won't Stop: A History of the Hip-Hop Generation. London, UK: Ebury Press, 2007.

Chang, Vanessa. "Records that Play: The Present Past in Sampling Practice." Popular Music 28 no 2 (2009): 143-159.

Chuck D. "Blues: The Footprint of Popular Music." In Martin Scorsese Presents the Blues, edited by Guralnick, Peter, Robert Santelli, Holly George-Warren, and Christopher John Farley, 280-1. New York, NY: Amistad, 2003.

Collins, Steve. "Waveform Pirates: Sampling, Piracy and Musical Creativity." Journal on the Art of Record Production, 3 no 1 (2008).

Demers, Joanna. "Sampling the 1970s in Hip-Hop." Popular Music 22 no 1 (2003): 41-56.

Evans, David. "Musical Innovation in the Blues of Blind Lemon Jefferson." Black Music Research Journal 20 no 1 (2000): 83-116. 
Gazaway, Amerigo. Interview by author. Skype interview. London, UK, November 8, 2016.

George, Nelson. Hip Hop America. New York, NY: Viking Penguin, 1998.

Goodwin, Andrew. "Sample and Hold: Pop Music in the Digital Age of Reproduction." Critical Quarterly 30 no 3 (1988): 34-49.

Grem, Darren E. "“The South Got Something to Say": Atlanta's Dirty South and the Southernization of Hip-Hop America." Southern Cultures 12 no 4 (2006): 55-73.

Guralnick, Peter, Robert Santelli, Holly George-Warren, and Christopher John Farley, eds. Martin Scorsese Presents the Blues: A Musical Journey. New York, NY: Amistad, 2003.

Harkins, Paul. "Transmission Loss and Found: The Sampler as Compositional Tool." Journal on the Art of Record Production 4 no 1 (2009).

Harkins, Paul. "Appropriation, Additive Approaches and Accidents: The Sampler as Compositional Tool and Recording Dislocation." Journal of the International Association for the Study of Popular Music 1 no 2 (2011): 1-19.

Harling, Danielle. "Bun B Breaks Down Origins Of "Trill" With A\$SAP Rocky." Hip Hop DX. Accessed August 24, 2019. http://hiphopdx.com/news/id.25756/title.bun-b-breaks-down-origins-of-trill-with-aap-rocky.

Hughes, Bryn. "Harmonic Expectations in Twelve-Bar Blues Progressions." PhD diss. Florida State University, 2011.

Krims, Adam. Rap Music and the Poetics of Identity. Cambridge, UK: Cambridge University Press, 2000.

Kulkarni, Neil. The Periodic Table of Hip Hop. London, UK: Ebury Press, 2015.

Levin, Marc. "Godfathers and Sons." In Martin Scorsese Presents the Blues, edited by Guralnick, Peter, Robert Santelli, Holly George-Warren, and Christopher John Farley, 186-7. New York, NY: Amistad, 2003. 
Marshall, Wayne. "Giving up Hip-hop's Firstborn: A Quest for the Real after the Death of Sampling." Callaloo 29 no 3 (2006): 868-892.

McLeod, Kembrew. “How Copyright Law Changed Hip Hop: An Interview with Public Enemy’s Chuck D and Hank Shocklee." Stay Fee! Magazine. Accessed August 24, 2019.

http://www.alternet.org/story/18830/how_copyright_law_changed_hip_hop.

Moorefield, Virgil. The Producer as Composer: Shaping the Sounds of Popular Music. Cambridge, MA: The MIT Press, 2010.

Morey, Justin, and Phillip McIntyre. "The Creative Studio Practice of Contemporary Dance Music Sampling Composers." Dancecult: Journal of Electronic Dance Music Culture 6 no 1 (2014): 41-60.

Navas, Eduardo. Remix Theory: The Aesthetics of Sampling. Berlin, Germany: Birkhäuser, 2012.

Quinlan, Thomas. “Abdominal \& The Obliques: Sitting Music.” Exclaim. Accessed August 24, 2019. http://exclaim.ca/music/article/abdominal_obliques-sitting_music.

Reiff, Corbin. "Texas Rap Meets Memphis Blues on the B.B. King/UGK Mashup LP The Trill Is Gone." AV Club. Accessed August 24, 2019. http://www.avclub.com/article/texas-rap-meets-memphis-blues-bbkingugk-mashup-Ip-227228.

Roberts, Randall. "Weekend Mixtape: The Pharcyde Collides with Tribe Called Quest." Los Angeles Times. Accessed August 24, 2019. http://articles.latimes.com/2012/sep/14/entertainment/la-et-ms-weekendmixtape-pharcyde-tribe-called-quest-20120914.

Rodgers, Tara. "On the Process and Aesthetics of Sampling in Electronic Music Production." Organised Sound 8 no 3 (2003): 313-320.

Rose, Tricia. Black Noise: Rap Music and Black Culture in Contemporary America. Hanover, NH: Wesleyan University Press, 1994. 
Rothenbuhler, Eric W. “For-the-Record Aesthetics and Robert Johnson's Blues Style as a Product of Recorded Culture." Popular Music 26 no 1 (2006): 65-81.

Schloss, Joseph G. Making Beats: The Art of Sample-based Hip-Hop. Middletown, CT: Wesleyan University Press, 2014.

Serrano, Shea. The Rap Year Book: The Most Important Rap Song From Every Year Since 1979, Discussed, Debated, and Deconstructed. New York, NY: Abrams Image, 2015.

Sewell, Amanda. "A Typology of Sampling in Hip-Hop." PhD diss. Indiana University, 2013.

Soul Mates. "The Trill Is Gone (Prod. by Amerigo Gazaway)." Bandcamp. Accessed August 24, 2019. https://soulmatesproject.bandcamp.com/album/the-trill-is-gone-prod-by-amerigo-gazaway.

Swiboda, Marcel. "When Beats Meet Critique: Documenting Hip-Hop Sampling as Critical Practice." Critical Studies in Improvisation 10 no 1 (2014): 1-11.

Toop, David. Rap Attack 3: African Rap to Global Hip Hop, 3rd edn. London, UK: Serpent's Tail, 2000.

Warner, Timothy. Pop Music - Technology and Creativity: Trevor Horn and the Digital Revolution. New York, NY: Routledge, 2016.

Williams, Justin. Rhymin' and Stealin': Musical Borrowing in Hip-hop. Ann Arbor, MI: University of Michigan Press, 2014.

Zagorski-Thomas, Simon. The Musicology of Record Production. Cambridge, UK: Cambridge University Press, 2014.

Zak III, Albin J. The Poetics of Rock: Cutting Tracks, Making Records. Berkeley, CA: University of California Press, 2001. 


\section{Discography}

A Tribe Called Quest, The Pharcyde, Amerigo Gazaway. Bizzare Tribe - A Quest To The Pharcyde. Gummy Soul BZTVOX, 2012, vinyl.

Abdominal and The Obliques. Sitting Music. Pinwheel Music PM 102, 2012, compact disc.

Blakroc. Blakroc. BlakRoc Records VVR725594, 2009, vinyl.

Brown, James. Funky Drummer. King Records 45-6290, 1970, vinyl.

Dr. Dre. 2001. Aftermath Entertainment / Interscope Records 490 823-2, 1999, compact disc.

Dr. Dre. The Chronic. Interscope Records 7567-92233-2, 1992, compact disc.

Enemy, Public. It Takes a Nation of Millions to Hold Us Back. Def Jam Recordings 527 358-2, 1988, compact disc.

Enemy, Public. Fear of a Black Planet. Def Jam Recordings, CBS 466281 2, 1990, compact disc.

Gazaway, Amerigo. B.B. \& The Underground Kingz: The Trill is Gone. Soul Mates Records, 2015, 18 x File, FLAC, MP3, 320Kbps.

Hawkins, Roy. The Thrill Is Gone: The Legendary Modern Recordings. Ace CHD-754, 2000, compact disc.

Johnson, Robert. The Complete Recordings. Sony BMG Music Entertainment 88697 296752, 1990, compact disc.

King, Albert. I'll Play the Blues for You. Stax STS-3009, 1972, vinyl.

King, B.B. The Thrill is Gone. Bluesy 45-61032, 1969, vinyl.

King, Freddie. Woman Across the River / Help Me through the Day. Shelter Records 7333, 1973, vinyl.

Nas. Street's Disciple. Sony Urban Music 517724 9, 2004, compact disc. 
OutKast. Southernplayalisticadillacmuzik. LaFace Records 7300826019 2, 1994, compact disc.

Starr, Gang. Hard to Earn. Chrysalis 72438284352 8, 1994, compact disc.

The Friends of Charlie Patton. Masters of the Delta Blues. YAZOO 2002, 2002, compact disc.

Various. The Roots of Rap: Classic Recordings from the 1920's and 30's. YAZOO 2018, 1996, compact disc.

Walter, Little. His Best. Chess Records, MCA Records, Inc. CHD-9384, 1997, compact disc.

Waters, Muddy. Electric Mud. Chess CRLS.4542, 1968, vinyl.

Waters, Muddy. Hoochie Coochie Man. Epic, CBS 461186 1, 1988, vinyl.

Wolf, Howlin'. Blues From Hell. Not Now Music NOT2LP130, 2011, vinyl.

Wolf, Howlin'. His Best. Chess Records, Universal Music International Ltd. 329 375-2, MCD 09375, 1997, compact disc.

Zeppelin, Led. Led Zeppelin IV. Atlantic 8122796433, 1971, vinyl. 
${ }^{1}$ Common cited in Levin, Marc, "Godfathers and Sons," in Martin Scorsese Presents the Blues, eds. Guralnick, Peter, Robert Santelli, Holly George-Warren, and Christopher John Farley (New York, NY: Amistad, 2003), 187.

2 In Various, The Roots of Rap: Classic Recordings from the 1920's and 30's, YAZOO 2018, 1996, compact disc.

${ }^{3}$ In Nas, Street's Disciple, Sony Urban Music 517724 9, 2004, compact disc.

${ }^{4}$ Abdominal and The Obliques, Sitting Music, Pinwheel Music PM 102, 2012, compact disc.

${ }^{5}$ Amerigo Gazaway, B.B. \& The Underground Kingz: The Trill is Gone, Soul Mates Records, 2015, 18 x File, FLAC, MP3, 320Kbps.

${ }^{6}$ For example: Tricia Rose, Black Noise: Rap Music and Black Culture in Contemporary America (Hanover, NH: Wesleyan University Press, 1994); Peter Guralnick, Robert Santelli, Holly George-Warren, and Christopher John Farley, eds., Martin Scorsese Presents the Blues: A Musical Journey (New York, NY: Amistad, 2003); Jeff Chang, Can't Stop Won't Stop: A History of the Hip-Hop Generation (London, UK: Ebury Press, 2007).

${ }^{7}$ Chang, Can't Stop Won't Stop: A History of the Hip-Hop Generation, 13.

${ }^{8}$ Muddy Waters, Electric Mud, Chess CRLS.4542, 1968, vinyl.

${ }^{9}$ Chuck D, "Blues: The Footprint of Popular Music," in Martin Scorsese Presents the Blues, eds. Guralnick, Peter, Robert Santelli, Holly George-Warren, and Christopher John Farley (New York, NY: Amistad, 2003), 281.

${ }^{10}$ Chuck D, "Blues: The Footprint of Popular Music," in Martin Scorsese Presents the Blues, eds. Guralnick, Peter, Robert Santelli, Holly George-Warren, and Christopher John Farley (New York, NY: Amistad, 2003), 280.

${ }^{11}$ A break or break-beat refers to the rhythmical breakdown of a record occupied solely by drums. DJs would extend the break-beat's duration by using two copies of the record on two turntables and switching continuously between the two breakdown segments.

${ }^{12} \mathrm{MC}$ stands for Master of Ceremony, and later Microphone Controller, both referring to rapper in this context.

${ }^{13}$ See, for example: Nelson George, Hip Hop America (New York, NY: Viking Penguin, 1998); David Toop, Rap Attack 3: African Rap to Global Hip Hop, 3rd edn. (London, UK: Serpent's Tail, 2000); Chang, Can't Stop Won't Stop: A History of the Hip-Hop Generation; Shea Serrano, The Rap Year Book: The Most Important Rap Song From Every Year Since 1979, Discussed, Debated, and Deconstructed (New York, NY: Abrams Image, 2015); Neil Kulkarni, The Periodic Table of Hip Hop (London, UK: Ebury Press, 2015).

${ }^{14}$ James Brown, Funky Drummer, King Records 45-6290, 1970, vinyl. 
${ }^{15}$ The second most sampled drum break is the intro from "When the Levee Breaks" from Led Zeppelin, Led Zeppelin IV, Atlantic 8122796433, 1971, vinyl-ironically a Memphis Minnie cover, bringing us back full circle to the Blues. ${ }^{16}$ Boom Bap is a subgenre of Hip Hop, referring onomatopoetically to the sound and rhythm of a heavy bass drum and snare (generally over sparse instrumentation). Typically, a sampled break-beat would be supported by synthetic kick and snare drum layers, frequently courtesy of a Roland TR-808 drum machine.

${ }^{17}$...providing an alternative to sampling practices partly as a reaction to newly applied legal restrictions. The Bomb Squad-known for their production work with Public Enemy-and Dr. Dre are notable examples of producers who consciously altered their process and style in response to the 1991 lawsuit involving Biz Markie's "Alone Again." See, for example: Kembrew McLeod, “How Copyright Law Changed Hip Hop: An Interview with Public Enemy’s Chuck D and Hank Shocklee," Stay Fee! Magazine, accessed August 24, 2019, http://www.alternet.org/story/18830/how_copyright_law_changed_hip_hop; Steve Collins, “Waveform Pirates: Sampling, Piracy and Musical Creativity," Journal on the Art of Record Production 3 no 1 (2008); Amanda Sewell, "A Typology of Sampling in Hip-Hop," PhD diss. (Indiana University, 2013).

${ }^{18}$ Domino cited in Joseph G. Schloss, Making Beats: The Art of Sample-based Hip-Hop (Middletown, CT: Wesleyan University Press, 2014), 164.

${ }^{19}$ Vanessa Chang, "Records that Play: The Present Past in Sampling Practice," Popular Music 28 no 2 (2009): 147. ${ }^{20}$ Interpolation refers to the studio re-creation of performances and sonics of an existing recording, which avoids breaching mechanical (phonographic) copyright, whilst still in use of the original composition (publishing rights).

${ }^{21}$ See, for example: Rose, Black Noise: Rap Music and Black Culture in Contemporary America; McLeod, "How Copyright Law Changed Hip Hop: An Interview with Public Enemy's Chuck D and Hank Shocklee"; Wayne Marshall, “Giving up Hip-hop's Firstborn: A Quest for the Real after the Death of Sampling," Callaloo 29 no 3 (2006): 868-892; Collins, "Waveform Pirates: Sampling, Piracy and Musical Creativity"; Schloss, Making Beats: The Art of Samplebased Hip-Hop.

${ }^{22}$ Simon Zagorski-Thomas, The Musicology of Record Production (Cambridge, UK: Cambridge University Press, 2014).

${ }^{23}$ Marshall, “Giving up Hip-hop's Firstborn: A Quest for the Real after the Death of Sampling,” 880.

${ }^{24}$ For example: Joanna Demers, "Sampling the 1970s in Hip-Hop," Popular Music 22 no 1 (2003): 41-56; Timothy Warner, Pop Music - Technology and Creativity: Trevor Horn and the Digital Revolution (New York, NY: Routledge, 2016); Virgil Moorefield, The Producer as Composer: Shaping the Sounds of Popular Music (Cambridge, MA: The 
MIT Press, 2010); Eduardo Navas, Remix Theory: The Aesthetics of Sampling. (Berlin, Germany: Birkhäuser, 2012); Justin Morey and Phillip McIntyre, "The Creative Studio Practice of Contemporary Dance Music Sampling Composers," Dancecult: Journal of Electronic Dance Music Culture 6 no 1 (2014): 41-60.

${ }^{25}$ Eric W. Rothenbuhler, “For-the-Record Aesthetics and Robert Johnson's Blues Style as a Product of Recorded Culture," Popular Music 26 no 1 (2006): 78.

${ }^{26}$ Albin J. Zak III, The Poetics of Rock: Cutting Tracks, Making Records (Berkeley, CA: University of California Press, 2001), 73.

${ }^{27}$ From Nas, Street's Disciple.

${ }^{28}$ From Muddy Waters, Hoochie Coochie Man, Epic, CBS 461186 1, 1988, vinyl.

${ }^{29}$ Amerigo Gazaway, B.B. \& The Underground Kingz: The Trill is Gone.

${ }^{30}$ B.B. King, The Thrill is Gone, Bluesy 45-61032, 1969, vinyl.

${ }^{31}$ From Abdominal and The Obliques, Sitting Music.

32 From Nas, Street's Disciple.

${ }^{33}$ Rothenbuhler, "For-the-Record Aesthetics and Robert Johnson's Blues Style as a Product of Recorded Culture," 71.

${ }^{34}$ Digital Audio Workstation software.

35 'Chopped' is a commonly used term for edited or truncated and then re-arranged in hip hop production terminology.

${ }^{36}$ Four studios have been used for recording (DARP Studios in Atlanta; Electric Lady Studios and Sony Music Studios in New York), and mixing the track (Circle House Studios in Miami).

37 James Brown, Funky Drummer.

${ }^{38}$ Brandon Caldwell, "UGK/B.B. King Mashup 'The Trill Is Gone' Is as Awesome as You Think It Is," Houston Press, accessed August 24, 2019, http://www.houstonpress.com/music/ugk-bb-king-mashup-the-trill-is-gone-is-asawesome-as-you-think-it-is-7887211.

${ }^{39}$ Corbin Reiff, "Texas Rap Meets Memphis Blues on the B.B. King/UGK Mashup LP The Trill Is Gone," AV Club, accessed August 24, 2019, http://www.avclub.com/article/texas-rap-meets-memphis-blues-bb-kingugk-mashup-lp227228. 
${ }^{40}$ Randall Roberts, "Weekend Mixtape: The Pharcyde Collides with Tribe Called Quest," Los Angeles Times, accessed August 24, 2019, http://articles.latimes.com/2012/sep/14/entertainment/la-et-ms-weekend-mixtapepharcyde-tribe-called-quest-20120914.

${ }^{41}$ Soul Mates, "The Trill Is Gone (Prod. by Amerigo Gazaway)," Bandcamp, accessed August 24, 2019, https://soulmatesproject.bandcamp.com/album/the-trill-is-gone-prod-by-amerigo-gazaway.

${ }^{42}$ Amerigo Gazaway, interview by author, Skype interview (London, UK, November 8, 2016).

${ }^{43}$ In an interview with the author, Gazaway details how he accesses the needed samples for his "conceptual collaborations" from multiple sources: available multi-tracks, isolating the left and right sides of a stereo master, locating extended live performance versions and sampling solos and exposed instruments from these; furthermore, he purposely samples B.B. King's Lucille guitar and treats it as a separate character in his arrangements.

${ }^{44}$ From Roy Hawkins, The Thrill Is Gone: The Legendary Modern Recordings, Ace CHD-754, 2000, compact disc, written by Roy Hawkins and Rick Darnell.

${ }^{45}$ Freddie King, Woman Across the River / Help Me through the Day, Shelter Records 7333, 1973, vinyl.

${ }^{46}$ Albert King, I'll Play the Blues for You, Stax STS-3009, 1972, vinyl.

${ }^{47}$ The album that is credited with putting Southern Rap on the map is OutKast, Southernplayalisticadillacmuzik, LaFace Records 7300826019 2, 1994, compact disc (see, for example, Darren E.Grem, “"'The South Got Something to Say": Atlanta's Dirty South and the Southernization of Hip-Hop America," Southern Cultures 12 no 4 (2006): 5573), complete with live performances of slowed-down southern soul meeting synthetic drum machine programming.

${ }^{48}$ Gazaway regards DJ Screw and Pimp C as pioneers of the Southern Rap sensibility, a notion that is shared by the hip hop community at large.

${ }^{49}$ Gazaway, interview by author.

${ }^{50}$ Beer and Sandywell define trans-morphing as "the creation of trans-genres by morphing across genres [...] This process generates a hybrid genre as the performer is simultaneously positioned in two or more genres". In David Beer and Barry Sandywell, "Stylistic Morphing: Notes on the Digitisation of Contemporary Music Culture," Convergence: The International Journal of Research into New Media Technologies 11 no 4 (2005): 115.

${ }^{51}$ The track further abuses the pitch-tempo analogy at 5:12, down to Fm and 65bpm.

${ }^{52}$ Gazaway, interview by author. 
${ }^{53}$ For more on trill, see Bun B's interview in Danielle Harling, "Bun B Breaks Down Origins Of "Trill" With A\$AP Rocky," Hip Hop DX, accessed August 24, 2019, http://hiphopdx.com/news/id.25756/title.bun-b-breaks-downorigins-of-trill-with-aap-rocky.

${ }^{54}$ Gazaway, interview by author.

55 Thomas Quinlan, “Abdominal \& The Obliques: Sitting Music,” Exclaim, accessed August 24, 2019, http://exclaim.ca/music/article/abdominal_obliques-sitting_music.

${ }^{56}$ Andy Bernstein, interview by author, Skype interview (London, UK, May 21, 2016).

${ }^{57}$ Bernstein, interview by author.

58 Bernstein, interview by author.

59 'Spill' in studio recording refers to the leakage of sonic content reaching a microphone positioned closest to the intended source from surrounding instruments.

${ }^{60}$ Bernstein, interview by author.

${ }^{61}$ DJs momentarily mute records for rhythmical effect using a crossfade control on their mixer during live performances, and in the practice of turntablism this is referred to as a 'cut'; it is often emulated on studio recordings by automation or using the mute button on a mixing console, or via various editing practices in software.

${ }^{62}$ Evans discusses various manifestations of this very characteristic when comparing Blind Lemon Jefferson with his contemporaries; highlighting Jefferson's innovations he details:

Jefferson's practice of prolonging the singing of certain notes and thereby stretching the standard twelvebar form is illustrated in virtually all of his blues using an $A A B$ stanza pattern. In these he also contributes to the stretching by playing extended guitar figures in response to his vocal lines.

In David Evans, "Musical Innovation in the Blues of Blind Lemon Jefferson," Black Music Research Journal 20 no 1 (2000): 90.

${ }^{63}$ Although recording to a click-track is atypical of blues sessions of the referenced era, the rationale behind this decision has been to aid sampling on a much larger scale than typically practiced. For most sample-based rap productions, a smaller number of samples are chosen from the same record and the variations in timing on the original performances can be negotiated though time-based manipulation. But for the 125 samples chosen from the original here, some degree of synchronization had to be maintained for the sampling phase to remain feasible. 
${ }^{64}$...from the predominantly straight-eighth patterns audible on the Freddie King and B.B. King examples above, to the more swung-sixteenth patterns performed by Al Jackson Jr. for Albert King at Stax.

65 The recording process was designed to honor tracking practices and appropriate instrumental sources representative of the era. The resulting channel list is as follows:

1. Bass drum

2. Snare drum

3. Middle tom

4. Mono overhead (option)

5. Stereo overhead (left)

6. Stereo overhead (right)

7. Drum room microphone

8. Shaker

9. Fretless bass

10. Rhodes

11. Upright piano (left)

12. Upright piano (right)

13. Clean electric guitar (rhythm)

14. Fuzz electric guitar (rhythm)

15. Clean and fuzz electric guitar (lead)

${ }^{66}$ The MPC Renaissance is a descendant of 1988's MPC60 and a mainstay in the current arsenal of Hip Hop production tools. Over the past two decades, the growing literature on Hip Hop musicology has paid ample tribute to Akai's range of MPCs, acknowledging their pivotal influence on the methodologies of Rap production. The technology combines sampling, drum-programming and MIDI-sequencing functionality, which has been embraced by practitioners ever since the release of the standalone MPC60 in 1988 and until its more recent computerdependent incarnations manifested in a multitude of current controllers and DAWs.

${ }^{67}$ The MPC operating script uses programs as groupings of multiple samples, sharing a number of user-definable parameters, such as polyphony, effects and output assignments.

${ }^{68}$ For example, Andrew Goodwin, "Sample and Hold: Pop Music in the Digital Age of Reproduction," Critical Quarterly 30 no 3 (1988): 34-49. 
${ }^{69}$ For example: Tara Rodgers, “On the Process and Aesthetics of Sampling in Electronic Music Production,” Organised Sound 8 no 3 (2003): 313-320; Paul Harkins, "Transmission Loss and Found: The Sampler as Compositional Tool," Journal on the Art of Record Production 4 no 1 (2009); Paul Harkins, "Appropriation, Additive Approaches and Accidents: The Sampler as Compositional Tool and Recording Dislocation," Journal of the International Association for the Study of Popular Music 1 no 2 (2011): 1-19; Justin Williams, Rhymin' and Stealin': Musical Borrowing in Hip-hop (Ann Arbor, MI: University of Michigan Press, 2014); Schloss, Making Beats: The Art of Sample-based Hip-Hop; Marcel Swiboda, "When Beats Meet Critique: Documenting Hip-Hop Sampling as Critical Practice," Critical Studies in Improvisation 10 no 1 (2014): 1-11.

${ }^{70}$ For example: Collins 2008; McLeod 2004.

${ }^{71}$ See, for example: Rose, Black Noise: Rap Music and Black Culture in Contemporary America; Schloss, Making Beats: The Art of Sample-based Hip-Hop.

72 The company itself pays tribute to its heritage (and sampling heritage in general) by including four options for modelling vintage sampler behaviour; that of the Akai MPC3000, the MPC60 and two variations for the E-mu SP1200.

${ }^{73}$ This echoes Gazaway's method described above, but it is also typical of hip hop practice in general, as a means to further distance one's output from the recognizability of the source and arrive at tempi appropriate for the subgenre in question: here, the vision of a more harmonically rich hip hop production lends itself to a Southern Rap sensibility, which frequents slower tempi.

${ }^{74}$ DJ Premier's work on Gang Starr's Hard to Earn (1994) is a prime demonstration of this function.

${ }^{75}$ In the case on hand, a Hammond organ part was added in post-production to support these harmonic suggestions.

${ }^{76}$ Schloss, Making Beats: The Art of Sample-based Hip-Hop, 159.

${ }^{77}$ For a stimulating discussion of The Roots' position on this problem see: Marshall, “Giving up Hip-hop's Firstborn: A Quest for the Real after the Death of Sampling."

${ }^{78}$ Kulkarni defines the Golden Age as "an era in which sampling hit a dizzying new depth of layered complexity and innovation" and "a sublime 10-year period from 1988 to 1998 in which hip hop was artistically more free than it had ever been before" in Kulkarni, The Periodic Table of Hip Hop, 78.

${ }^{79}$ Schloss, Making Beats: The Art of Sample-based Hip-Hop, 151. 
${ }^{80}$ For example: Adam Krims, Rap Music and the Poetics of Identity (Cambridge, UK: Cambridge University Press, 2000); Kyle Adams, "The Musical Analysis of Hip-Hop," in The Cambridge Companion to Hip-Hop, ed. Justin Williams (Cambridge, UK: Cambridge University Press, 2015), 118-134.

${ }^{81}$ Adams, "The Musical Analysis of Hip-Hop," 118.

82 Zagorski-Thomas, The Musicology of Record Production, 45-6. 